\title{
Labor market dynamics when effort depends on wage growth comparisons*
}

\author{
David de la Croix ${ }^{1} \quad$ Franz Palm ${ }^{2} \quad$ Jean-Pierre Urbain ${ }^{2}$ \\ First draft, April 1996 \\ This version: September 1996
}

\begin{abstract}
We present an efficiency wage model in which workers' effort depends on the level and on the growth rate of their wage relative to an alternative wage. Using data for four countries (US, UK, FR, GY), the implications of the model are examined and are found to be in accordance with the information in the non-stationary data. The restrictions implied by the model dynamics are not rejected by the data. Moreover the structural parameters are found to be constant through time, indicating that, although very simple, the model is likely to be robust to the Lucas critique. One interesting result is that the workers' effort depends less on relative wages growth and more on relative wage levels in the US than in the three European countries analyzed.
\end{abstract}

JEL Classification number: E24

Keywords: Efficiency wages, effort function, cointegration, GMM.

*We are thankful to Paul Olbrechts, Jan Ladang and Nicole Mernier for their help in collecting the data. A preliminary version of this paper was presented at the HCM conference (contract nr. ERBCHRXCT 40658) on the stylized facts of business cycles in the E.C. (Hydra, Greece, april 1996). We also thank Fatemeh Shadman-Mehta for her comments about an earlier draft of the paper. The first author aknowledges the support of the grant "Actions de Recherche Concertée" 93/98-162 of the Ministry of Scientific Research (Belgian French Speaking Community).

1 National Fund for Scientific Research (Belgium) and University of Louvain, Department of Economics, Place Montesquieu 3, B-1348 Louvain-la-Neuve. Ph + 3210473453 . Fax + 3210473945 . E-mail delacroix@ires.ucl.ac.be.

2 University of Limburg, Department of Quantitative Economics, P.O. Box 616, 6200 MD Maastricht, The Netherlands. 


\section{Introduction}

The contrast between the US pattern of the labour market and its European counterpart has attracted wide attention (see e.g. Card, Kramarz and Lemieux (1996)). Indeed, in the last two decades, the US labour market was characterized by constant or even declining real wages and rising employment, while the European labour market experienced steadily rising real wages and falling employment, implying a substantial and persistent high level of unemployment.

There are many reasons for doubting that the time series properties of wages and employment can be understood in terms of the outcome of a competitive labour market. Indeed, dynamic models with perfect competition systematically fail to reflect the low response of wages to shocks and the high response of employment. Attempts to tackle this failure within the Walrasian paradigm are proposed in Christiano and Eichenbaum (1992), Burnside, Christiano and Rebelo (1993) and Fairise and Langot (1994) and further evaluated using European data by Fève and Langot (1994).

Departures from the Walrasian framework account for some of these facts (An exploratory computable model is proposed by Bénassy (1995)). Among the various ways to improve modelling the labour market, efficiency wage theories seem a very promising one. In these models, the firm chooses the wage so as to motivate its employees, to reduce its turnover costs or to attract a larger share of skilled workers to its work basin. As stressed in the recent survey of MacLeod and Malcomson (1995), these models are able to explain why wages may not respond to some shocks and/or display asymmetric behaviour over the business cycle and why employment varies so much.

In this paper, we develop an efficiency wage model which accounts for the following issues. First, various studies tend to show that, in addition to the usual comparison of the level of firm's wages with outside wages, workers compare also their current situation with that in the past. ${ }^{1}$ Past situations are used as a benchmark to evaluate current outcomes. As a consequence workers are interested in rising wage profiles, as shown in Loewenstein and Sicherman (1991) and Frank and Hutchens (1993). ${ }^{2}$ Second, a large number of empirical studies find that many macroeconomic and sectoral time series contain a unit root and that the unemployment rates display a high degree of persistence. Our model will be formulated in such a way that it is consistent with the presence of non-stationarity in the time series related to output, employment and wages and with a high degree of unemployment persistence.

Accordingly we propose a dynamic model in which a representative firm chooses employment and a wage level designed to motivate its employees. The effort of these employees depends both on the level and on the growth rates of wages compared to those of the alternative wages (i.e. in the rest of their sector). With the aim to understand wage

\footnotetext{
${ }^{1}$ This is supported by various empirical analyses. For instance an interesting study has been carried out by Lord and Hohenfeld (1979). They compared the performance records of 23 major league baseball players who, for contract reasons, were paid less one season than they were the previous season. Thus, using their own salaries for the previous year as a basis of comparison, they were expected to have felt underpaid. The study shows that these players lowered their performance; in particular, they had lower batting averages, hit fewer home runs, and had fewer runs-batted-in. (from Greenberg and Ornstein (1984)).

${ }^{2}$ Kotowitz and Portes (1974) and de la Croix, Palm and Pfann (1996) apply the same idea to unions.
} 
and employment dynamics, the implications of this model are confronted with data for manufacturing sectors in US, Germany, Great-Britain and France. Using the information contained in the observed stochastic and deterministic trends, a cointegration (Engle and Granger, 1987) restriction is derived from the theoretical model and used to estimate a first set of parameters. If cointegration is not rejected, the remaining parameters are obtained from the estimation of the Euler equations by the Generalized Method of Moments (Hansen, 1982). If cointegration is rejected, the adequate unit root is imposed, and the set of parameters is estimated in one step by GMM. We also analyse systematically the issue of parameter constancy, both at the level of the cointegration restriction and at the level of the GMM estimation.

The paper is organized as follows. In section 2, the theoretical model is presented. Section 3 describes the data and some summary statistics. In Section 4, results of the empirical analysis are presented. Section 5 contains some concluding remarks.

\section{The model}

The production function is

$$
y_{t}=f\left(a_{t}, \tilde{l}_{t}, k_{t}\right),
$$

where $y_{t}$ is production and $k_{t}$ the capital stock. The stochastic variable $a_{t}$ is a productivity shock. $\tilde{l}_{t}$ represents efficient hours of work which are given by

$$
\tilde{l}_{t}=e^{\mu t} h_{t} l_{t}
$$

where $l_{t}$ denotes hours input and $h_{t}$ effort per hour. The parameter $\mu$ measures the growth rate of deterministic labour-saving technical progress. The production function is supposed to have a CES form:

$$
f(.)=\psi e^{a_{t}}\left[(1-\alpha)\left(e^{\mu t} h_{t} l_{t}\right)^{\frac{\sigma-1}{\sigma}}+\alpha\left(k_{t}\right)^{\frac{\sigma-1}{\sigma}}\right]^{\frac{\sigma}{\sigma-1}}
$$

The parameter $\sigma>0$ is the elasticity of substitution between efficient hours and capital. $\alpha \in] 0,1[$ and $\psi>0$. Two kinds of popular specifications for the technical progress are allowed for: (a) a deterministic labour saving technical progress (i.e. Harrod neutral) growing at a rate $\mu,(\mathrm{b})$ a stochastic technical progress $a_{t}$ affecting total factor productivity and generated by the following scheme:

$$
a_{t}=\phi a_{t-1}+z_{t},
$$

where $z_{t}$ is assumed to be i.i.d. with $E\left\{z_{t}\right\}=0$. The empirical analysis will be designed to evaluate the importance of both types of technical progress and to test whether $a_{t}$ contains a unit root, i.e. $\phi=1$.

As usually assumed in efficiency wage models, the representative firm chooses its wages in order to increase the effort of its employees. The effort function has been introduced by Solow (1979) and used since then by many others, see e.g. Danthine and Donaldson (1990). In the standard approach, the effort function depends on the level of wages compared to the level of the alternative wage: $h_{t}\left(w_{t}^{c} / \bar{w}_{t}^{c}\right)$. Assuming furthermore that the alternative wage is equal to the wage times the probability of finding a job, i.e. one minus the 
unemployment rate, $\bar{w}_{t}^{c}=\left(1-u_{t}\right) w_{t}^{c}$, the level of effort depends on the unemployment rate. The firm's optimality conditions states that, at equilibrium, the elasticity of effort with respect to wages should be one (this relation is known as the Solow (1979) condition). The implications of this relation are not easily in accordance with a high degree of persistence in unemployment. Indeed the optimality condition contains a variable which is not far from being non-stationary so that it has to include other elements in order to become empirically plausible. The standard approach in which effort is a function of the relative wage is thus extended by assuming that the effort function also depends on the growth of the wage in the firm compared to the growth of the alternative wage, i.e. the wage paid by other firms of the sector weighted by the probability of finding a job in these firms:

$$
h_{t}=\left(\frac{w_{t}^{c}-\bar{w}_{t}^{c}}{\bar{w}_{t}^{c}}\right)^{\nu}\left(1+\gamma\left(\frac{w_{t}^{c}}{w_{t-1}^{c}}-\frac{\bar{w}_{t}^{c}}{\bar{w}_{t-1}^{c}}\right)\right) \text {, }
$$

in which

$$
w_{t}^{c}=\frac{w_{t}}{p_{t}^{c}} \quad \text { and } \quad \bar{w}_{t}^{c}=\frac{\bar{w}_{t}}{p_{t}^{c}}
$$

are respectively the hourly real wage paid by the firm and the average hourly real wage in the rest of the sector and the consumption price index is used as deflator. The parameter $\nu<1$ measures the extent to which effort is sensitive to the difference in percent between the worker's wage and the alternative wage. The parameter $\gamma$ measures the extent to which effort is sensitive to the difference between the growth of the worker's wage and the growth of the alternative wage. If $\gamma=0$, one retrieves a standard formulation of efficiency wage models, see e.g. Summers (1988).

Real profits of the firm are:

$$
s_{t}=y_{t}-w_{t}^{p} l_{t}-\frac{p_{t}^{i}}{p_{t}} i_{t}
$$

where $i_{t}$ is gross investment and $p_{t}^{i}$ its price. $w_{t}^{p}$ denotes the real wage when the price index of output $p_{t}$ is used as a deflator:

$$
w_{t}^{p}=\frac{w_{t}}{p_{t}}
$$

The capital stock obeys the standard accumulation rule:

$$
k_{t}=(1-\delta) k_{t-1}+i_{t},
$$

where $\delta$ is the depreciation rate. At time $t$, the firm chooses plans for wages, hours input and capital input so as to maximize the expected current real value of future profits given the information $\Omega_{t}$ available at time $t$ :

$$
\max _{w_{t}, l_{t}, k_{t}} \mathrm{E}\left[\sum_{i=t}^{\infty} R_{t}^{i} s_{i} \mid \Omega_{t}\right] .
$$

The uncertainty comes from the realisation of the future exogenous variables among which technological shocks, prices and alternative wages. $R_{t}^{i}$ is the discount factor between time $t$ and time $i . \Omega_{t}$ is the information set at time $t$ including current and past values of the 
exogenous variables and past values of the endogenous variables. The first order necessary conditions for a maximum are:

$$
\begin{aligned}
w_{t}^{p} & =\frac{\partial f}{\partial \tilde{l}_{t}} e^{\mu t} h_{t} \\
w_{t}^{p} & =\frac{\partial f}{\partial \tilde{l}_{t}} e^{\mu t} h_{t}\left(\frac{\nu w_{t}^{c}}{w_{t}^{c}-\bar{w}_{t}^{c}}+\gamma X_{t}\right)-\mathrm{E}_{t}\left[R_{t}^{t+1} \frac{l_{t+1}}{l_{t}} \frac{\partial f}{\partial \tilde{l}_{t+1}} e^{\mu(t+1)} h_{t+1} \gamma X_{t+1}\right] \\
\frac{p_{t}^{i}}{p_{t}} & =\mathrm{E}_{t}\left[(1-\delta) R_{t}^{t+1} \frac{p_{t+1}^{i}}{p_{t+1}}\right]+\frac{\partial f}{\partial k_{t}}
\end{aligned}
$$

with

$$
\begin{aligned}
\frac{\partial f}{\partial \tilde{l}_{t}} & =\psi^{1-1 / \sigma}(1-\alpha) e^{(1-1 / \sigma) a_{t}}\left(\frac{y_{t}}{e^{\mu t} h_{t} l_{t}}\right)^{\frac{1}{\sigma}} \\
\frac{\partial f}{\partial k_{t}} & =\psi^{1-1 / \sigma} \alpha e^{(1-1 / \sigma) a_{t}}\left(\frac{y_{t}}{k_{t}}\right)^{\frac{1}{\sigma}} \\
X_{t} & =\frac{w_{t}^{c} / w_{t-1}^{c}}{1+\gamma\left(w_{t}^{c} / w_{t-1}^{c}-\bar{w}_{t}^{c} / \bar{w}_{t-1}^{c}\right)}
\end{aligned}
$$

where $\mathrm{E}_{t}\{\cdot\}=\mathrm{E}\left\{. \quad \mid \Omega_{t}\right\}$.

The dynamics of the system results from the dynamics of the technological shock, the effort function and the accumulation of capital. The first equation states that workers are hired up to the point where the marginal productivity of labour in efficiency units is equal to the real wage. The second equation is a modified Solow condition. If $\gamma=0$ it states that the wages should be set such that the elasticity of effort to wages is equal to one, or stated otherwise, that the wage of the firm is a mark-up over the alternative wage

$$
(1-\nu) w_{t}^{c}=\bar{w}_{t}^{c}
$$

When $\gamma \neq 0$ this condition has to be modified to take into account the fact that workers are also interested in relative wage growth. The third equation is the standard optimal investment rule.

Equation (6) also gives rise to an interesting interpretation in the framework of a symmetric equilibrium. Indeed, in the majority of efficiency wage models the alternative wage $\bar{w}_{t}$ is given at the symmetric equilibrium by

$$
\bar{w}_{t}=\left(1-(1-\beta) u_{t}\right) w_{t},
$$

where $u_{t}$ is the unemployment rate, whith $1-u_{t}$ measuring the probability of finding a job in the rest of the economy. The parameter $\beta$ is inversely related to the relative importance of unemployment in determining the worker's outside opportunities. Using (5) to replace $\frac{\partial f}{\partial \tilde{l}_{t}} e^{\mu t} h_{t}$ by its value, and using (8), we find:

$$
0=\frac{1}{\gamma}\left(\frac{\nu}{(1-\beta) u_{t}}-1\right)+X_{t}-\mathrm{E}_{t}\left[R_{t}^{t+1} \frac{w_{t+1}^{p} l_{t+1}}{w_{t}^{p} l_{t}} X_{t+1}\right] .
$$


Notice that, at the symmetric equilibrium, the variable $X$ depends on the growth rates of wages and unemployment. Loosely speaking, the parameter $1 / \gamma$ measures the importance of the level of unemployment in the wage formation process. If $1 / \gamma$ is very low, the fact that $u_{t}$ could depart from a value given by $\nu /(1-\beta)$ will not affect significantly the optimal rule of the firm, and the growth rate of wages depends only on the growth rate of unemployment. If $1 / \gamma$ is high, the level of unemployment is important and affects the optimal growth rate of wages. To summarize, if workers attach much weight to wage growth in determining their effort level, the optimal wage set by the firm will not react much to the level of unemployment. In a general equilibrium model, this characteristic may in turn lead to hysteresis or persistence in unemployment.

Let us briefly consider the implications of these first order conditions for the estimation method. Considering that the growth rate of real wages is stationary and assuming that unemployment is stationary, in which case effort is itself stationary, we may consider two different cases, depending on whether the technical progress is stationary or not. In both cases, a natural way to estimate the Euler equations of the model is to use the Generalized Method of Moments (GMM) proposed by Hansen (1982). When applying GMM we impose the unit roots and/or the cointegration relationships established in the first step of the empirical analysis. By imposing these restrictions, we want to avoid estimating unit roots and satisfy ergodicity and mixing conditions and thereby minimize the risk for GMM estimates and GMM-based tests to have non-standard asymptotic properties. A similar approach is used, a.o., by Ogaki (1992) and de la Croix and Urbain (1996). This two-step approach generalizes the one proposed by Dolado, Galbraith and Banerjee (1991) to non-linear Euler equations with I(1) variables. We now investigate in turn the case in which the stochastic technical progress is stationary, i.e. $\phi<1$, (case A) and the case in which this technical progress has a unit root, i.e. $\phi=1$ (case B).

Let us assume that the technical progress is stationary $(|\phi|<1)$. In this situation and if the exogenous variables are I(1) processes, the theoretical model implies that real wages $w_{t}^{p}$ and productivity $y_{t} / l_{t}$ should be cointegrated I(1) processes. Similarly, if prices and wages are $\mathrm{I}(2)$, then they should cointegrate to yield an $\mathrm{I}(1) w_{t}^{p}$ which should then cointegrate with the I(1) $y_{t} / l_{t}$. The model remains valid if all the series are stationary.

Indeed, a cointegration restriction between real wages and average labour productivity is implicit in (5):

$$
\sigma \ln \left[w_{t}^{p}\right]-\ln \left[(1-\alpha)^{\sigma} \psi^{\sigma-1}\right]-\ln \left[y_{t} / l_{t}\right]+(1-\sigma) \mu t=v_{t}
$$

where we define

$$
v_{t} \stackrel{\text { def }}{=}(\sigma-1)\left(a_{t}+\ln h_{t}\right)
$$

Since $a_{t}$ and $h_{t}$ only contain stationary variables, (9) defines a cointegration restriction. In order to get reliable estimates of the parameters of this model it is useful to proceed in two steps. In the first step we estimate this cointegration relation by an appropriate method. We obtain superconsistent estimates $\hat{\sigma}$ and for $\hat{\mu}$. These point estimates can be used in a second GMM step to get estimates of $\gamma, \phi$ and $\nu$. Using (10), the first order conditions (5)-(6) can be written as: 


$$
\begin{aligned}
& \frac{\hat{v}_{t}-\phi \hat{v}_{t-1}}{\hat{\sigma}-1}-\nu \ln \left[\frac{w_{t}^{c}-\bar{w}_{t}^{c}}{\bar{w}_{t}^{c}}\right]-\ln \left[1+\gamma\left(\frac{w_{t}^{c}}{w_{t-1}^{c}}-\frac{\bar{w}_{t}^{c}}{\bar{w}_{t-1}^{c}}\right)\right] \\
& +\phi \nu \ln \left[\frac{w_{t-1}^{c}-\bar{w}_{t-1}^{c}}{\bar{w}_{t-1}^{c}}\right]+\phi \ln \left[1+\gamma\left(\frac{w_{t-1}^{c}}{w_{t-2}^{c}}-\frac{\bar{w}_{t-1}^{c}}{\bar{w}_{t-2}^{c}}\right)\right]=z_{t} \quad(11 \\
& \left.\frac{1}{\gamma}\left(\frac{\nu w_{t}^{c}}{w_{t}^{c}-\bar{w}_{t}^{c}}-1\right)+\frac{\frac{w_{t}^{c}}{w_{t-1}^{c}}}{1+\gamma\left(\frac{w_{t}^{c}}{w_{t-1}^{c}}-\frac{\bar{w}_{t}^{c}}{\bar{w}_{t-1}^{c}}\right)}-\frac{w_{t+1}^{p} l_{t+1}}{w_{t}^{p} l_{t}} \frac{R_{t}^{t+1} \frac{w_{t+1}^{c}}{1+\gamma\left(\frac{w_{t+1}^{c}}{w_{t}^{c}}-\frac{\bar{w}_{t+1}^{c}}{\bar{w}_{t}^{c}}\right)}=e_{t+1},(1}{1+l_{t}}\right)
\end{aligned}
$$

where the error term of (11) is simply the innovation in the productivity shock and the error term of (12) represents forecast errors and is defined as

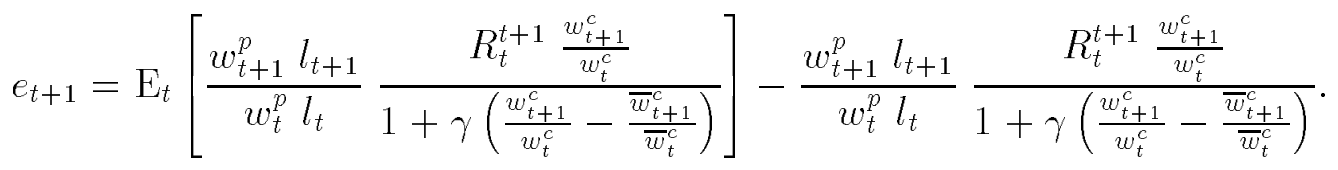

When estimating the Euler equations (11) -(12), we shall assume that the productivity shock $z_{t}$ has already occurred and is known to the firm when it takes its decision. The shock is of course an unobservable for the investigator. Therefore, $z_{t}$ is treated as a disturbance in equation (11). ${ }^{3}$

Let $I_{t}$ be a subset of $\Omega_{t}$ consisting of observed lagged stationary variables. The moment restrictions used for the GMM estimation of the parameters can be summarized as:

$$
\mathrm{E}\left[\left(z_{t} e_{t+1}\right)^{\prime} \otimes I_{t}\right]=0 .
$$

Finally notice that for reasons of flexibility equation (7) will not be included in the GMM estimation. This will result in a loss of efficiency but not in inconsistency as in the sequel the capital stock will be treated as an endogenous variable for which an instrumental variable is used.

If the technical progress is integrated of order one, in order to impose this unit root it is necessary to take equation (5) in first differences:

$$
\begin{array}{r}
\frac{\sigma \Delta \ln \left[w_{t}^{p}\right]-\Delta \ln \left[y_{t} / l_{t}\right]+(1-\sigma) \mu}{\sigma-1}-\nu \Delta \ln \left[\frac{w_{t}^{c}-\bar{w}_{t}^{c}}{\bar{w}_{t}^{c}}\right] \\
-\Delta \ln \left[1+\gamma\left(\frac{w_{t}^{c}}{w_{t-1}^{c}}-\frac{\bar{w}_{t}^{c}}{\bar{w}_{t-1}^{c}}\right)\right]=z_{t},
\end{array}
$$

where the error term of (14) is simply the innovation in the random walk $a_{t}$. The parameters $\sigma, \mu$, and $\gamma$ should be estimated using (12) in which the error term has the same interpretation as before. The restrictions used in GMM are the same as in (13).

\section{The data}

We use quarterly seasonally adjusted data on manufacturing sectors in the United-States, Germany, Great-Britain and France (industrial production, hours of work, hourly compensation, aggregate unemployment rate, price index). A detailed description and the

\footnotetext{
${ }^{3}$ The assumption implies that the expectation error and the shock $z_{t}$ are uncorrelated. This condition is not explicitly used in the estimation.
} 
source of these data are provided in Appendix A. The sample is the same for all countries and covers the period 1963:3-1994:4.

In the case where the stochastic process representing the technological progress is assumed to be a stationary AR(1) process (Case A), our empirical analysis will consist of different steps. For each country, we proceed as follows: $(i)$ determination of the order of integration of the individual series, (ii) investigation of the presence of cointegration between $w_{t}^{p}$ and $y_{t} / l_{t}$ in order to obtain point estimates of $\sigma$ and $\mu$, (iii) given that these are super-consistently estimated in the case of cointegration, we may then fix these parameters at their point estimates $\hat{\sigma}$ and $\hat{\mu}$ and estimate the remaining parameters of (11) and (12), i.e. $\phi, \gamma$ and $\nu$, in a second step by Generalized Methods of Moments. The last step of the empirical analysis is then the investigation of the potential parameter (non)-constancy of our retained specification and estimation results.

Accordingly we first compute ${ }^{4}$ some standard univariate unit root tests in order to obtain empirical evidence in favor or against the assumption of stochastic trends in our data. Notice that under the assumption of a stationary technical progress, and the assumption of I(2) nominal wages and prices, one of the implication of our theoretical model is that both real wages and productivity should be co-integrated $\mathrm{I}(1)$ processes. The Appendix B presents the outcome of standard Dickey-Fuller $(1979,1981)$ tests denoted by $D F_{(.)}$, and Phillips and Perron (1988) tests $Z_{(.)}$. Since nominal variables are possibly represented by I(2) processes, the test statistics are computed for the second differences, the first differences as well as for the level of the series. Two versions of the statistics are considered: with both a constant and a linear time trend in the underlying regression model, denoted by a subscript $t r$, and with a constant term alone, denoted by the subscript cst. For the level (i.e. I(1) versus I(0)), we compute the statistics for the null of a random walk with drift against the alternative of a trend stationary process. For the first difference we consider both the case with and without trend while for the second difference we only retain the case with a constant as it seems unlikely to have $\mathrm{I}(2)$ series with drift. From the table in this appendix, it appears that if we base the analysis on the $Z$ tests, for almost all series and all countries, we may not reject the hypothesis of a single unit root in our series. If the results are based on $D F$ type of statistics, there is some evidence in favor of $\mathrm{I}(2)$ prices and wages, but again the outcomes favor the $\mathrm{I}(1)$ nature of real wages. Note that in accordance with many empirical studies ${ }^{5}$, unemployment rates again are found to be I(1) processes over the sample period. ${ }^{6}$ Employment on the other hand is possibly trend stationary for the US (with a negative trend) while the outcomes for the other countries again favor the I(1) assumption. Real wages and labour productivity are always best described by I(1) processes. Note finally that Phillips-Perron's tests reject the unit root hypothesis for all the interest rates series.

\footnotetext{
${ }^{4}$ All the empirical calculations have been performed with Gauss 3.2.0 \& TSP 4.3.

${ }^{5}$ See e.g. Hall (1986), Jaeger and Parkinson (1994) and de la Croix and Lubrano (1996).

${ }^{6}$ This again raises the issue of the usefulness of standard univariate unit root test for time series like unemployement rate. Whether one should follow a more general approach to the persistency in unemployment, allowing for stationary long memory processes, i.e. fractional processes, or for some form of non-linearity in the dynamics is however outside the scope of this study.
} 
Table 1: Cointegration results (FMLS)

\begin{tabular}{|ccccccc|}
\hline & Cnst & $(1-\sigma) \mu$ & $\sigma$ & Lc & MeanF & SupF \\
\hline US & -0.2165 & 0.0083 & 0.2865 & 0.3444 & 2.9204 & 5.6111 \\
& $(0.0105)$ & $(0.0002)$ & $(0.0929)$ & & & \\
UK & -0.1097 & 0.0049 & 0.8476 & 0.5917 & 4.4923 & 8.2295 \\
& $(0.0337)$ & $(0.0008)$ & $(0.1414)$ & & & \\
FR & -0.1568 & 0.0047 & 0.6264 & 0.2522 & 2.9542 & 6.6024 \\
& $(0.0263)$ & $(0.0008)$ & $(0.0933)$ & & & \\
GY & -0.0893 & 0.0050 & 0.4275 & 0.3954 & 4.1440 & 7.0142 \\
& $(0.0290)$ & $(0.0008)$ & $(0.0727)$ & & & \\
\hline
\end{tabular}

\section{Estimation results}

\subsection{Cointegration Analysis}

There exists a wide range of approaches to cointegration testing and estimation in the literature, ranging from simple Engle and Granger (1987) static regressions to multivariate analyses. While the latter methods -like the popular Johansen (1991) maximum likelihood framework- have a number of clear statistical advantages in terms of their efficient use of the sample information and the underlying optimal inference that can be conducted, they are usually characterized by some particular maintained assumptions which we cannot retain for our analysis. The assumption of a linear finite order Gaussian VAR model which underlies for example Johansen's framework is an assumption which we can hardly maintain given our theoretical set-up. A possible alternative is therefore to use asymptotically median-unbiased estimators that do not require a specific parametric representation of the short run dynamic and that nevertheless lead to optimal inference (in the sense of Phillips (1991)). The latter can for example be achieved by means of semi-parametric corrections for endogeneity and serial correlation which in our case would stem from the presence of $\ln h_{t}$ in $v_{t}$, see (9). In this paper, we choose to use the Fully Modified Least Squares (FMLS) estimators proposed by Phillips and Hansen (1990) and Hansen (1992b) as well as Park (1992) Canonical Cointegration Regressions (CCR) which yield asymptotically optimal estimates of the non-stationary components and are asymptotically equivalent to FIML parametric estimators but without requiring an explicit parametrization of the short run dynamics. Given the first order condition, we choose productivity as the regressand and real wages as the regressor. From (9) we see that we should also allow for the possibility of a linear trend in the cointegration regression. The resulting parameters, whose significance can be tested using fully modified t-statistics, are then simply $\sigma$ for the real wages and $(1-\sigma) \mu$ for the linear trend.

Table 1 reports the cointegration results obtained from the use of the FMLS estimator computed with a Quadratic Spectral kernel function and an automatic plug-in bandwidth parameter. The Appendix $\mathrm{C}$ reports some comparable results obtained by using different estimation techniques such as CCR, straightforward OLS as well as FMLS both with and without VAR(1) prewhitening. As pointed out for example by Haug (1995) and Cappucio 
and Lubian (1994), the way by which we estimate the long run covariance matrix used to correct the estimates can play an important role, especially in finite samples. Following the existing Monte Carlo evidence reported in Andrews and Monahan (1992), Cappucio and Lubian (1994), our FMLS estimates are computed using a quadratic spectral estimator with the automatic plug-in bandwidth parameter. ${ }^{7}$

The last columns of Table 1 report several statistics. $L_{c}$ is Hansen (1992a) LM test for the null of cointegration against the alternative of no-cointegration based on the constancy of the intercept of the cointegration regression. Asymptotic critical values are reported in Hansen (1992a). The $5 \%$ critical value is approximately equal to 0.575 in our case. The columns $S u p F$ and Mean $F$ are parameter constancy statistics derived by Hansen (1992a). These statistics are in the spirit of sequences of standard Chow tests for parameter constancy. We compute a standard Chow test for a fixed break date and then consider the sequence of test statistics by varying the location of the break. The final SupF test is then the supremum of the sequence. Under the null of parameter constancy of the cointegration regression, the asymptotic distribution of SupF depends on the number of regressors in the cointegration regression and on the specification of the deterministic components. MeanF is computed from the same sequence, shares the same null hypothesis but is likely to be more powerful against gradual changes in the parameters. The respective $5 \%$ critival values are approximately given by 15.2 and 6.2 respectively.

From this Table we see that the null of cointegration, as tested by means of $L_{c}$, cannot be rejected for the US, France and Germany while the results for the UK are much more on the borderline which might indicate, for the UK at least, a possible violation of the assumption made in Case A. This could be an indication of the inappropriateness of the assumption of a stationary AR(1) technological progress which could contain a unit root and hence imply a lack of cointegration - see (9). Case B will therefore be of interest, at least for the UK. This is partly confirmed by the results reported in Appendix C. Notice also that for all countries, Table 1 shows that the assumption of parameter constancy cannot be rejected using Hansen (1992a)'s SupF and MeanF statistics.

\subsection{GMM analysis - case A}

Given the non-linear dynamic rational expectations formulation of the theoretical model, the non-linear IV version of GMM seems a natural method for estimating the remaining parameters of the Euler equations. In analogy to Engle and Granger (1987) two-step method, we presume that the asymptotic properties of the second step GMM procedure are not affected by the first step estimation since the estimators for $\sigma$ and $\mu$ from cointegrating regressions converge faster than the GMM estimators. For each country, the two equations (11)-(12) are thus estimated jointly imposing the adequate cross restrictions.

The value of $\beta$ in a fully worked out model would depend positively on the utility of leisure, the value of unemployment benefits and negatively on the duration of unemployment. However, such a richer specification is very difficult to implement here due to a lack

\footnotetext{
${ }^{7}$ The advantage of using the plug-in bandwidth parameter is that it avoids the arbitrariness of chosing a priori the order of truncation. Although much of the motivation for using prewhitening is the practical attractiveness of the approach, as it enables one to estimate more easily the long run covariance matrix, it should be noted that in our case the prewhitening only seems to affect the results for the UK.
} 
Table 2: GMM estimates (case A)

\begin{tabular}{|ccccccc|}
\hline & $\phi$ & $\nu$ & $1 / \gamma$ & $J_{\text {test }}$ & $t_{\phi=1}$ & SupLR \\
\hline US & 0.8733 & 0.0048 & 0.0396 & 17.1647 & -3.9090 & 5.1904 \\
& $(0.0324)$ & $(0.0003)$ & $(0.0079)$ & {$[0.3091]$} & {$[0.0031]$} & \\
UK & 0.8678 & 0.0027 & 0.0156 & 15.0098 & -3.6061 & 10.2658 \\
& $(0.0366)$ & $(0.0006)$ & $(0.0057)$ & {$[0.4507]$} & {$[0.0072]$} & \\
FR & 0.7361 & 0.0016 & 0.0114 & 15.0771 & -4.0601 & 16.3890 \\
& $(0.0650)$ & $(0.0004)$ & $(0.0021)$ & {$[0.4459]$} & {$[0.0021]$} & \\
GY & 0.8674 & 0.0015 & 0.0162 & 20.3443 & -3.7344 & 10.7749 \\
& $(0.0355)$ & $(0.0003)$ & $(0.0043)$ & {$[0.1591]$} & {$[0.0051]$} & \\
\hline
\end{tabular}

of quarterly data concerning these variables for manufacturing. We shall consider here $\beta$ as a constant that we arbitrarily set to 0.9 . This value can be seen as a replacement ratio corrected for the disutility of work.

Concerning the discount factor, we use a varying discount factor of the form:

$$
\left\{\begin{array}{l}
R_{t}^{t}=1 \\
R_{t}^{i}=\prod_{j=t}^{i}\left(\frac{1}{1+r_{j}}\right), i>t
\end{array}\right.
$$

where $r_{j}$ is the real interest rate. The model has also been estimated using a constant (imposed) discount factor of 0.99 . This leads to the same conclusions as the analysis of the main text, and the corresponding results are presented in appendix D.

As discussed in Hall (1993) and Ogaki (1993a), the GMM often appears to be sensitive to the chosen instrument set. In particular, for a fixed sample size, increasing the number of instruments increases the number of overidentifying restrictions but, at the same time, may introduce substantial bias in the estimates of the coefficients. For case A, the retained instrument set includes

$$
I_{t}=\left\{\text { cst, trend, } \operatorname{trend}^{2}, \hat{v}_{t-1}, \Delta u_{t-1}, \Delta \ln w_{t-1}^{c}, \Delta \ln l_{t-1}, \hat{v}_{t-2}, \Delta \ln w_{t-2}^{c}\right\},
$$

where $\hat{v}_{t}$ is the residual of the cointegration regression as defined in (9). The presence of trend ${ }^{2}$ stems from the non-linear structure of the Euler equations. With this instrument set, the number of overidentifying restrictions is equal to 15. As suggested by Kocherlakota (1990) and Nelson and Startz (1990), we iterate on the optimal weighting matrix (i.e. the inverse of the covariance matrix of the orthogonality conditions) in order to improve the properties of the estimators.

The results of the GMM estimation of (11)-(12) are presented in Table 2. Robust standard errors are reported in parentheses. These are obtained on the basis of the heteroscedasticity and autocorrelation consistent covariance matrix of Newey and West (1987). $J$ is Hansen (1982)'s test for overidentifying restrictions, asymptotically $\chi^{2}$ distributed with $q$ degrees of freedom, where $q$ is the number of overidentifying restrictions. Corresponding p-values are reported between square brackets. 
Table 3: GMM estimates (case B)

\begin{tabular}{|ccccccc|}
\hline & $\sigma$ & $(1-\sigma) \mu$ & $\nu$ & $1 / \gamma$ & $J_{\text {test }}$ & SupLR \\
\hline US & 0.9092 & 0.0061 & 0.0054 & 0.0338 & 22.1043 & 23.2113 \\
& $(0.0994)$ & $(0.0009)$ & $(0.0004)$ & $(0.0095)$ & {$[0.2274]$} & \\
UK & 1.0546 & 0.0025 & 0.0024 & 0.0140 & 17.5961 & 30.7501 \\
& $(0.1080)$ & $(0.0014)$ & $(0.0007)$ & $(0.0064)$ & {$[0.4825]$} & \\
FR & 0.7099 & 0.0042 & 0.0011 & 0.0123 & 17.6005 & 28.8220 \\
& $(0.0982)$ & $(0.0016)$ & $(0.0004)$ & $(0.0022)$ & {$[0.4822]$} & \\
GY & 0.2046 & 0.0071 & 0.0012 & 0.0247 & 27.7115 & 59.1336 \\
& $(0.0619)$ & $(0.0014)$ & $(0.0002)$ & $(0.0054)$ & {$[0.0666]$} & \\
\hline
\end{tabular}

Given that, following the cointegration analysis, we do not reject the constancy of the long-run parameters, we analyse the constancy of the short-run parameters conditionally on the estimates of the long-run parameters. The analysis considers a sequence of $L R$ type tests, see Andrews (1993), computed as the difference between the partial-sample GMM objective function evaluated at the full sample GMM and at the partial sample-GMM estimators. $^{8}$

The structural break is allowed to occur in the interval of time [0.15, 0.85]. SupLR is thus the supremum of the sequence of the quasi likelihood ratio type test for parameter constancy. The critical values are 14.15 at $5 \%$ and 17.68 at $1 \%$ for a model with three parameters.

From Table 2, we may draw the following conclusions. First, all coefficients have the expected sign and are significantly different from zero (except $\nu$ for the UK). Second, according to the $J_{\text {test }}$, the over-identifying restrictions arising from the model are never rejected at $5 \%$. Third, the parameter $\phi$ is always significantly lower than 1 , even if we use a Dickey-Fuller distribution instead of a student distribution for $t_{\phi=1}$. This is consistent with the cointegration analysis for three countries out of four. For the UK, the parameter $\phi$ of the $\mathrm{AR}(1)$ process of technological shocks is also significantly lower than one, although the evidence in favour of cointegration is less clearcut. Fourth, parameter constancy is moderately rejected for France (at $5 \%$ but not at 1\%). It is not rejected in the three remaining countries. Fifth, $1 / \gamma$ is significantly larger for the US than for the three European countries. The interpretation of this is discussed later in the text.

\subsection{GMM analysis - case B}

We now present the estimation results of the model under the assumption that the productivity shock contains a unit root. We have seen that this assumption may seem realistic for the UK. To facilitate cross-country comparisons, the estimation under case B has been carried out for each of the four countries. The instrument set differs slighlty from case A,

\footnotetext{
${ }^{8}$ As suggested by Gallant (1987), $L R$ is computed as the normalized difference between the constrained objective function and the unconstrained one. The constrained estimation is computed with the weighting matrix provided by the unconstrained estimation.
} 
since we have no cointegration residuals to include in the instrument set:

$$
\begin{array}{r}
I_{t}=\left\{\text { cst, trend, } \text { trend }^{2}, \Delta u_{t-1}, \Delta \ln w_{t-1}^{c}, \Delta \ln l_{t-1}, \Delta \ln \frac{y_{t-1}}{l_{t-1}},\right. \\
\left.\Delta \ln \frac{y_{t-2}}{l_{t-2}}, \Delta \ln w_{t-2}^{c}, \Delta \ln w_{t-1}^{p}, \Delta \ln w_{t-2}^{p}\right\} .
\end{array}
$$

This leads to 15 overidentifying restrictions. The results are presented in Table 3 . As before, all coefficients have the expected sign and are significantly different from zero. The point estimates are not very different from the analysis under $\phi<1$ except those of $\sigma$. According to the $J_{\text {test }}$, the over-identifying restrictions arising from the model are not rejected in the first three countries and at the margin for Germany.

The parameter constancy hypothesis is rejected for all countries (the critical value for a model with four parameters is 16.45 at $5 \%$ and 20.71 at $1 \%$ ).

The cointegration tests presented earlier together with the parameter constancy results favors the idea that for three countries (US, FR and GY) the model with a stationary productivity shock and an estimation method in two step gives better results. For the UK, there is no evidence in favour of cointegration, and the estimation in one step by GMM gives acceptable results although parameter constancy is rejected. We thus retain the assumption that $\phi=1$ for the UK although the alternative can also be supported on the basis of different arguments. Note that the estimates for $\gamma$ and $\nu$ do not differ substantially between the two alternatives.

An analysis of the residual correlations of the models in cases $\mathrm{A}$ and $\mathrm{B}$ indicates that there is some serial correlation and cross-correlation present in the disturbances. For France and for the US, the residual first order correlation is of importance and leads to significant values for the Ljung-Box test. For the UK and Germany, residual correlations at lags three and/or four are significant in some instances as well. This could result from seasonality still present in the seasonally adjusted series. Of course, in order to deal with the residual serial correlation, one can further refine the dynamics of the model. For instance, effort could be assumed to depend on a comparison between lagged annual growth rates of wages instead of the lagged quarterly rates. Such a specification would rely on the assumption that workers compare the evolution of wages over a longer period of time. Alternatively, a more general specification for the process of the technology shocks would account for serial correlation in $\hat{z}_{t}$. These extensions are left for future research. However, in view of the moderate size of the residual serial correlations, we do not expect any substantial inconsistency to arise in GMM estimation.

\subsection{Cross-country comparison}

Considering the results of Table 2 and 3 , it may be important to proceed to a crosscountry comparisons of the parameters estimates which display some similarities and one interesting difference. The parameter $\gamma$ which measures the sensitivity of effort to wage growth comparisons is significantly lower in the US. On the other hand, the parameter $\nu$ is significantly larger in the US, reflecting that efforts depends more on the comparison between the levels of wages. The question that naturally arises is to know if we can impose the parameters $\nu$ and $\gamma$ to be the same for all three European countries. Exploiting the fact that the sample period is the same for the four countries, this issue can be addressed 
Table 4: GMM estimates: pooled countries

\begin{tabular}{|cccccc|}
\hline & $(1-\sigma) \mu$ & $\sigma$ & $\phi$ & $\nu$ & $1 / \gamma$ \\
\hline US & 0.0083 & 0.2865 & 0.9529 & 0.0063 & 0.1046 \\
& & & $(0.0151)$ & $(0.0001)$ & $(0.0103)$ \\
UK & 0.0014 & 1.1344 & 1.0000 & 0.0020 & 0.0153 \\
& $(0.0008)$ & $(0.0630)$ & & $(0.0003)$ & $(0.0041)$ \\
FR & 0.0047 & 0.6264 & 0.6633 & 0.0025 & 0.0173 \\
& & & $(0.0342)$ & $(0.0002)$ & $(0.0017)$ \\
GY & 0.0050 & 0.4275 & 0.8544 & 0.0011 & 0.0153 \\
& & & $(0.0216)$ & $(0.0002)$ & $(0.0028)$ \\
\hline
\end{tabular}

by estimating an eight equations model using a seemingly unrelated GMM procedure. In that case, the country specific restrictions are based on the orthogonality between the residuals and the country specific instruments, so that the instruments related to the three other countries are excluded.

The estimation results are presented in Table 4 in which $\phi$ as been set to 1 for the UK and $\sigma$ and $\mu$ are set to the values obtained with FMLS for the three other countries. The number of overidentying restrictions is 63 . The J-test gives a value of 50.5089 which allows us to not reject the overidentifying restrictions ( $p$-value $=0.8720)$. Using standard Wald-type tests, we cannot reject the hypothesis that $1 / \gamma^{U K}=1 / \gamma^{F R}=1 / \gamma^{G Y}$ (p-value $=0.7649)$. On the other hand, the restrictions that $\nu^{U K}=\nu^{F R}=\nu^{G Y}$ are rejected ( $\mathrm{p}-$ value $=0.0000$ ), while the less restrictive assumption that $\nu^{U K}=\nu^{F R}$ is much more close to the borderline case $(\mathrm{p}$-value $=0.1144)$. These tests imply that, with respect to the parameter $\gamma$, the countries can be classified in two blocks, the US on the one side with a relatively low effet of wage growth on effort, and the three European countries on the other side with a relatively high effect of wage growth on effort.

\section{Conclusion}

We proposed a dynamic model in which a representative firm chooses employment and a wage level designed to motivate its employees. The effort of these employees depends, first, on a comparison between the level of their wage and the level of the alternative wage and, second, on a comparison between the respective growth rates. The restrictions arising from this model have been confronted with data for manufacturing sectors in US, Germany, Great-Britain and France. From the theoretical model we derive a cointegration restriction between real wages and labour productivity, which is in agreement with the nonstationarities found in the data. Empirical evidence in favour of cointegration is found for the US, France and Germany, indicating that technical progress has been (trend) stationary in these countries. For these three countries, a first set of parameters is estimated by Fully-Modified Least Squares and the remaining parameters are obtained from the estimation of the Euler equations by GMM, given super-consistent estimates of the first set of parameters. For the United-Kingdom, the evidence from the cointegration 
analysis is less clear-cut. There is evidence in the data in favour of a unit root in the technological shock. We then estimate the full set of parameters in one step by GMM, although the alternative is also defendable.

The conclusion is threefold. First, the implications of the model seem in accordance with the non-stationarity present in the data and the restrictions imposed on the dynamics are not rejected. Second, the model is very simple but and given that parameter constancy is not rejected in three countries among four, it is relatively robust to the Lucas critique (from a practical point of view, parameter constancy appears indeed as a necessary but not sufficient condition for robustness to the Lucas critique). Third, the parameters of the US effort function are significantly different from those for European countries. Effort is less sensitive to wage growth comparisons in the US than in the three European countries. In these three countries, we may restrict the sensitivity parameter $\gamma$ to be the same. In the US, effort is more sensitive to the relative wage than in Europe. European workers seem more attached to previous wage conditions and put more weight on wage increases. According to our results, the optimal wage growth set by the firm is more sensitive to the level of unemployment in the US than in Europe.

Two limitations of the model are worth noting. First, in order to keep the number of parameters of the empirical model low, the specification of the alternative wages is the simplest possible. They only depend on wages in the manufacturing sector and on the level of unemployment. A more general formulation should include wages outside the manufacturing sectors and some variables related to unemployment (benefits, duration etc...). The inclusion of additional countries would be useful to further enrich the analysis. Second, as it has been discussed earlier in the text, because the technological shock has a very simple formulation and because the memory of workers is limited to one period, the dynamics of the model is very simple. As already indicated, further refining the dynamics of the effort function would also be interesting.

\section{References}

Andrews, D. (1993) "Test for parameter instability and structural change with unknown change point". Econometrica, 61:821-856.

Andrews, D. and C. Monahan (1992) "An improved heteroscedasticity and autocorrelation consistent covariance matrix". Econometrica, 60:953-966.

Bénassy, J.-P. (1995) "Money and wage contracts in an optimizing model of the business cycle". Journal of Monetary Economics, 35:303-315.

Burnside, C., L. Christiano and S. Rebelo (1993) "Labor hoarding and the business cycle". Journal of Political Economy, 101:245-273.

Cappucio, N. and D. Lubian (1994) "Fully modified estimation of cointegrating vectors via VAR prewhitening: a simulation study". Working Paper, University of Padoua.

Card, D., F. Kramarz and T. Lemieux (1996) "Changes in the relative structure of wages and employment: comparison of the United States, Canada and France". Working Paper, NBER. 
Christiano, L. and M. Eichenbaum (1992) "Current real business cycle theories and aggregate labor market fluctuations". American Economic Review, 82:430-450.

Danthine, J.-P. and J. Donaldson (1990) "Efficiency wages and the business cycle puzzle". European Economic Review, 34:1275-1301.

de la Croix, D. and M. Lubrano (1996) Are real interest rates responsible for unemployment in the eighties? a Bayesian analysis of cointegrated relationships with a regime shift. In T. Fomby and R. Hill, editors, Advances in Econometrics: Bayesian Methods Applied to Time Series. JAI press.

de la Croix, D., F. Palm and G. Pfann (1996) "A dynamic contracting model for wages and employment in three European economies". European Economic Review, 40:429-448.

de la Croix, D. and J.-P. Urbain (1996) "Intertemporal substitution in import demand and habit formation". Working Paper, Université catholique de Louvain.

Dickey, D. and W. Fuller (1979) "Distribution of the estimators for autoregressive time series with a unit root". Journal of the American Statistical Association, 74:427-431.

Dickey, D. and W. Fuller (1981) "Likelihood ratio test statistics for autoregressive time series with a unit root". Econometrica, 49:1057-1072.

Dolado, J., J. Galbraith and A. Banerjee (1991) "Estimating intertemporal quadratic adjustment cost models with integrated series". International Economic Review, 32:919936.

Engle, R. and C. Granger (1987) "Co-integration and error correction: representation, estimation and testing". Econometrica, 55:251-276.

Fairise, X. and F. Langot (1994) "Labor productivity and the business cycle: Can R.B.C. models be saved". European Economic Review, 38:1581-1594.

Fève, P. and F. Langot (1994) "The RBC model through statistical inference: an application with French data". Journal of Applied Econometrics, 9:S11-S35.

Frank, R. and R. Hutchens (1993) "Wages, seniority, and the demand for rising consumption profiles". Journal of Economic Behavior and Organization, 21:251-276.

Gallant, D. (1987) Nonlinear Statistical Models. John Wiley \& Sons.

Greenberg, J. and S. Ornstein (1984) Motivation in organizations. In R. Geen, W. Beatty and R. Arkin, editors, Human Motivation: Physiological, Behavioral, and Social Approaches. Allyn and Bacon.

Hall, A. (1993) Some aspects of generalized method of moments estimation. In G. Maddala, C. Rao and H. Vinod, editors, Handbook of Statistics, Vol. 11. Elsevier.

Hall, S. (1986) "An application of the Engle and Granger two-step estimation procedure to United Kindgom aggregate wage data". Oxford Bulletin of Economics and Statistics, 48:229-239. 
Hansen, B. (1992a) "Tests for parameter instability in regressions with I(1) processes". Journal of Business and Economic Statistics, 10:321-335.

Hansen, B. (1992b) "Efficient estimation and testing for cointegration vector with the presence of deterministic trends". Journal of Econometrics, 53:81-121.

Hansen, L. (1982) "Large sample properties of generalized method of moments estimators". Econometrica, 50:1029-1054.

Haug, A. (1995) "Tests for cointegration: a Monte Carlo comparison". Journal of Econometrics, forthcoming.

Jaeger, A. and M. Parkinson (1994) "Some evidence on hysteresis in unemployment rates". European Economic Review, 38:329-342.

Johansen, S. (1991) "Estimation and hypothesis testing of cointegration in vector Gaussian autoregressive models". Econometrica, 59:1551-1580.

Kocherlakota, N. (1990) "On tests of representative consumer asset pricing models". Journal of Monetary Economics, 26:285-304.

Kotowitz, Y. and R. Portes (1974) "The tax on wage increases". Journal of Public Economics, 3:112-132.

Loewenstein, G. and N. Sicherman (1991) "Do workers prefer increasing wage profiles?" Journal of Labor Economics, 9:67-84.

Lord, R. and J. Hohenfeld (1979) "Longitudinal field assessment of equity effects on the performance of major league baseball players". Journal of Applied Psychology, 64:19-26.

MacLeod, W. and J. Malcomson (1995) "Turnover costs, efficiency wages and cycles". Annales d'Economie et de Statistique, 37/38:55-74.

Nelson, C. and R. Startz (1990) "The distribution of the instrumental variable estimator and its t-ratio when the instrument is a poor one". Journal of Business, 63:125-140.

Newey, W. and K. West (1987) "A simple positive definite, heteroskedasticity and autocorrelation consistent covariance matrix". Econometrica, 55:703-708.

Ogaki, M. (1992) "Engel's law and cointegration". Journal of Political Economy, 100:1027-1046.

Ogaki, M. (1993a) Generalized method of moments: Econometric applications. In Maddala, Rao and Vinod, editors, Handbook of Statistics, Vol. 11. Elsevier.

Park, J. (1990) "Testing for unit roots and cointegration by variable addition". Advances in Econometrics, 8:107-133.

Park, J. (1992) “Canonical cointegrating regressions". Econometrica, 60:119-143.

Phillips, P. (1991) "Optimal inference in cointegrated systems". Econometrica, 59:283306. 
Phillips, P. and B. Hansen (1990) "Statistical inference in instrumental variables with I(1) processes". Review of Economic Studies, 57:99-124.

Phillips, P. and P. Perron (1988) "Testing for a unit root in time series regression". Biometrika, 75:335-346.

Solow, R. (1979) "Another possible source of wage stickiness". Journal of Macroeconomics, 1:79-82.

Summers, L. (1988) "Relative wages, efficiency wages, and Keynesian unemployment". AEA Papers and Proceedings, 78:383-386. 


\section{Table 5: Appendix A: data sources}

\begin{tabular}{|c|c|c|}
\hline \multicolumn{3}{|c|}{ US } \\
\hline$y_{t}$ & Output of manufacturing industries & Federal reserve bulletin \\
\hline$l_{t}$ & Worked hours in manufacturing industries & Bulletin des statistiques du travail \\
\hline$w_{t}$ & Hourly gains in manufacturing industries & Employment and earnings \\
\hline$p_{t}$ & Producer price index, finished goods & Business cycles indicators \\
\hline$p_{t}^{c}$ & Consumption price index & Federal reserve bulletin \\
\hline$u_{t}$ & Civilian unemployment rate & Federal reserve bulletin \\
\hline \multicolumn{3}{|c|}{$\mathbf{U K}$} \\
\hline$y_{t}$ & Output of manufacturing industries & Monthly digest \\
\hline$l_{t}$ & Worked hours in manufacturing industries & Employment gazette \\
\hline$w_{t}$ & Weekly gains in manufacturing industries & Employment gazette \\
\hline$p_{t}$ & Wholesale price of finished goods & Trade and industry \\
\hline$p_{t}^{c}$ & Consumption price index & Monthly digest \\
\hline$u_{t}$ & Unemployed as a percentage of active population & Trade and industry \\
\hline \multicolumn{3}{|c|}{ FR } \\
\hline$y_{t}$ & Output of manufacturing industries & OECD industrial production \\
\hline$l_{t}$ & Worked hours in manufacturing industries & Bulletin des statistiques du travail \\
\hline$w_{t}$ & $\begin{array}{l}\text { Hourly wage in transformation industries } \\
\text { (bef. 1973: all industries) }\end{array}$ & Bulletin mensuel de statistiques \\
\hline$p_{t}$ & Consumption price index of manufactured goods & Bulletin mensuel de statistiques \\
\hline$p_{t}^{c}$ & Consumption price index & Bulletin mensuel de statistiques \\
\hline$u_{t}$ & Unsatisfied employment demand & Bulletin mensuel de statistiques \\
\hline & Active population & OCDE stat. de la population active \\
\hline \multicolumn{3}{|c|}{ GY } \\
\hline$y_{t}$ & Output of manufacturing industries & Wirtschaft und statistik \\
\hline$l_{t}$ & Hourly productivity in manufacturing industries & Wirtschaft und statistik \\
\hline & Output of manufacturing industries & Wirtschaft und statistik \\
\hline$w_{t}$ & Hourly wages in manufacturing industries & Indikatoren zur Wirtschaftsenwicklung \\
\hline$p_{t}$ & Wholesale price of industrial products & Wirtschaft und statistik \\
\hline$p_{t}^{c}$ & Consumption price index & Wirtschaft und statistik \\
\hline$u_{t}$ & Unemployed persons & Wirtschaft und statistik \\
\hline & Active population & OCDE stat. de la population active \\
\hline
\end{tabular}




\section{Appendix B: Unit Roots Tests}

Note to Table:

- For Phillips-Perron non-parametric corrections, the long run variances are estimated using a Quadratic Spectral kernel function and an automatically plug-in bandwidth parameter. For the ADF tests, the augmentation lag length was chosen by minimising Akaike's AIC criteria.

- Two versions of the statistics are considered: with both a constant and a linear time trend in the underlying regression model, denoted by a subscript $t r$, and with a constant term alone, denoted by the subscript cst.

- Critical values for $D F$ and $Z$ tests are, for $T=100$, as follows: for $D F_{c s t}$ and $Z_{c s t}:-2.89$ and -2.58 at a $5 \%$ and $10 \%$ level respectively, For $D F_{t r}$ and $Z_{t r}:-3.45$ and -3.15 at a $5 \%$ and $10 \%$ level respectively. 
Table 6: Unit Roots Tests

\begin{tabular}{|c|c|c|c|c|c|c|c|c|c|}
\hline & \multicolumn{2}{|c|}{ Level } & \multicolumn{4}{|c|}{ 1st difference } & \multicolumn{2}{|c|}{ 2nd difference } \\
\hline & & $D F_{t r}$ & $Z_{t r}$ & $D F_{c s t}$ & $D F_{t r}$ & $Z_{c s t}$ & $Z_{t r}$ & $D F_{c s t}$ & $Z_{c s t}$ \\
\hline \multirow[t]{9}{*}{ US } & $w_{t}$ & -1.1849 & 1.3966 & -1.1342 & -2.0773 & -4.0610 & -4.7602 & -7.2155 & -2.5493 \\
\hline & $p_{t}$ & -1.4881 & -0.0171 & -2.4010 & -2.5713 & -6.4258 & -6.5821 & -7.5142 & -3.3493 \\
\hline & $p c_{t}$ & -1.1670 & -0.8691 & -2.5696 & -2.6794 & -4.4445 & -4.4833 & -5.0293 & -3.4161 \\
\hline & $w p_{t}$ & -3.0740 & -2.2464 & -3.7289 & -3.8152 & -10.8512 & -10.9112 & -4.4525 & -5.4035 \\
\hline & $w p c_{t}$ & -1.7347 & -1.8891 & -3.6617 & -4.8677 & -9.2254 & -9.9431 & -6.5120 & -6.0646 \\
\hline & $u_{t}$ & -2.3166 & -2.2643 & -3.5900 & -3.6434 & -6.3173 & -6.3351 & -4.5800 & -5.2302 \\
\hline & $l_{t}$ & -4.0170 & -4.0219 & -4.4680 & -4.4682 & -6.7856 & -6.8521 & -5.6772 & -5.6966 \\
\hline & $y_{t} / l_{t}$ & -2.4840 & -2.9362 & -7.3717 & -7.3377 & -12.5887 & -12.5820 & -5.8398 & -8.1838 \\
\hline & $R_{t}^{t+1}$ & -2.4626 & -7.6090 & -7.8826 & -7.8794 & -26.1260 & -26.1251 & -5.9469 & -12.2255 \\
\hline \multirow[t]{9}{*}{ UK } & $w_{t}$ & -1.3570 & -0.4601 & -2.4134 & -2.6079 & -10.2675 & -10.3900 & -4.4260 & -5.3070 \\
\hline & $p_{t}$ & -1.9831 & -0.9885 & -1.5924 & -1.7693 & -3.7167 & -3.8055 & -4.8564 & -3.0995 \\
\hline & $p c_{t}$ & -1.5058 & -0.1769 & -1.9694 & -2.1077 & -5.7318 & & -3.9362 & -3.7109 \\
\hline & $w p_{t}$ & -2.0609 & -1.9277 & -2.4738 & -2.4606 & -13.1659 & -13.1644 & -6.2746 & -7.9354 \\
\hline & $w p c_{t}$ & -2.3545 & -3.1686 & -5.0436 & -5.0210 & -15.0911 & -15.0919 & -5.8656 & -8.9315 \\
\hline & $u_{t}$ & -2.4074 & -2.2669 & -3.8951 & -3.9019 & -4.5466 & & -6.8523 & -4.2221 \\
\hline & $l_{t}$ & -2.5997 & -2.5479 & -4.6496 & -4.7059 & -7.5222 & -7.5599 & -3.9334 & -5.1269 \\
\hline & $y_{t} / l_{t}$ & -0.9840 & -0.8686 & -3.0787 & -3.2173 & -12.1875 & -12.2447 & -5.2667 & -7.0728 \\
\hline & $R_{t}^{t+1}$ & -1.6415 & -4.5955 & -4.8566 & -4.8692 & -14.7206 & -14.7188 & -6.6371 & -9.8317 \\
\hline \multirow[t]{9}{*}{$\mathrm{FR}$} & $w_{t}$ & -1.2084 & -1.7584 & -2.0953 & -1.8559 & -4.8009 & -5.5982 & -6.7899 & -3.0826 \\
\hline & $p_{t}$ & -1.4268 & -0.4494 & -2.4584 & -2.5614 & -3.5292 & -3.6284 & -5.4159 & -2.7073 \\
\hline & $p c_{t}$ & -1.3759 & -0.2043 & -1.4499 & -1.7545 & -3.4128 & -3.6455 & -7.4692 & -2.4470 \\
\hline & $w p_{t}$ & -1.0950 & -1.1186 & -4.9178 & -5.9839 & -10.0701 & -11.3330 & -5.7372 & -6.2882 \\
\hline & $w p c_{t}$ & -0.0654 & -0.5968 & -0.9790 & -6.4609 & -11.1015 & -12.7390 & -5.7901 & -6.9880 \\
\hline & $u_{t}$ & -2.5157 & -2.1399 & -2.3885 & -2.3804 & -9.2488 & -9.3036 & -5.1267 & -6.4811 \\
\hline & $l_{t}$ & -2.2237 & -1.6589 & -2.4855 & -2.6285 & -7.8215 & -8.0620 & -5.9762 & -5.3654 \\
\hline & $y_{t} / l_{t}$ & -1.8362 & -2.3646 & -6.1116 & -6.3673 & -14.8394 & -14.9942 & -5.3932 & -9.2897 \\
\hline & $R_{t}^{t+1}$ & -2.8153 & -6.0777 & -7.3726 & -7.3692 & -20.7181 & -20.7155 & -6.2498 & -10.4124 \\
\hline \multirow[t]{9}{*}{ GY } & $w_{t}$ & -0.1499 & -0.2089 & -8.5005 & -5.2263 & -19.1125 & -20.6173 & -5.6176 & -8.2858 \\
\hline & $p_{t}$ & -1.2499 & -0.9359 & -3.5472 & -3.5745 & -6.0524 & -6.0971 & -5.1118 & -4.5385 \\
\hline & $p c_{t}$ & -1.4118 & -0.6181 & -2.4384 & -2.5397 & -8.4869 & -8.5737 & -3.3256 & -6.2894 \\
\hline & $w p_{t}$ & -2.5072 & -2.0028 & -7.9615 & -8.6779 & -18.7870 & -19.6340 & -6.4307 & -8.6394 \\
\hline & $w p c_{t}$ & -1.2884 & -1.1355 & -8.1404 & -5.4314 & -20.2178 & -21.4309 & -5.9192 & -8.9585 \\
\hline & $u_{t}$ & -2.3198 & -1.8500 & -3.6825 & -3.6690 & -7.2390 & -7.2384 & -5.0055 & -5.1489 \\
\hline & $l_{t}$ & -2.5853 & -1.7999 & -4.4155 & -4.4055 & -13.0630 & -13.1264 & -6.4517 & -6.0712 \\
\hline & $y_{t} / l_{t}$ & -1.5402 & -1.7753 & -7.0574 & -7.4031 & -13.9536 & -14.3555 & -5.1193 & -7.7085 \\
\hline & $R_{t}^{t+1}$ & -3.1377 & -8.1322 & -4.8117 & -4.8279 & -16.3410 & -16.3410 & -5.8247 & -10.05 .54 \\
\hline
\end{tabular}




\section{Appendix C: Cointegration analysis}

All the results are obtained using the full sample for each country. For each case, we consider the estimation of the cointegrating vectors by means of the following estimation methods:

1. OLS: CRDW is the cointegration Durbin Watson statistic and $Z$ is Phillips-Oulliaris test for the null of no-cointegration based on the OLS estimation of the cointegation regression. The $5 \%$ critical value is approximately equal to -3.64 .

2. Fully Modified LS (Phillips and Hansen (1990)) where the long run variance/covariance matrix used to perform the non-parametric correction is estimated using a Quadratic Spectral kernel function and the bandwidth parameter is automatically selected following Andrews and Monahan (1992). We consider both the case with and without pre-whitening by means of a AR(1) filter.

3. CCR: the same applies than for FMLS

For the test statistics we report:

1. Phillips-Ouliaris $Z$ tests computed with a quadratic spectral kernel and where the bandwidth parameter is again automatically selected both with or without prewhitening,

2. Park (1990)'s H(p,q) test which test the null hypothesis that the cointegration residuals are well characterised by a $p$ th order trend stationary process against an alternative of $q$ th order trend polynomial. We computed both the statistics using the CCR and the FMLS residuals. These test statistics are asymptotically $\chi^{2}(p-q)$ distributed under the null. $H(0,1)$ is a test of the null hypothesis of deterministic cointegration since the restrictions tested implies that the cointegrating vector eliminates both the stochastic and the deterministic trends.

3. Hansen (1992a) test for parameter constancy among which the $L c$ tests which test the null of a unique cointegrating vector with constant parameters.

Table 7: OLS

\begin{tabular}{|ccccccc|}
\hline & Cnst & $(1-\sigma) \mu$ & $\sigma$ & CRDW & Z-prew & Z-noprew \\
\hline US & -0.2147 & 0.0082 & 0.2916 & 0.4154 & -3.5791 & -3.6929 \\
& $(0.0038)$ & $(0.0001)$ & $(0.0332)$ & & & \\
UK & -0.1367 & 0.0056 & 0.7273 & 0.2943 & -2.7997 & -2.8731 \\
& $(0.0123)$ & $(0.0003)$ & $(0.0514)$ & & & \\
FR & -0.1546 & 0.0047 & 0.6190 & 0.6291 & -4.5818 & -4.6995 \\
& $(0.0109)$ & $(0.0003)$ & $(0.0381)$ & & & \\
GY & -0.1162 & 0.0055 & 0.4036 & 0.3991 & -3.0743 & -3.2584 \\
& $(0.0110)$ & $(0.0003)$ & $(0.0272)$ & & & \\
\hline
\end{tabular}




\begin{tabular}{|c|c|c|c|c|c|c|}
\hline \multicolumn{7}{|c|}{ FMLS - Prewithening } \\
\hline & Cnst & $(1-\sigma) \mu$ & $\sigma$ & $\mathrm{Lc}$ & MeanF & SupF \\
\hline \multirow[t]{2}{*}{ US } & -0.2148 & 0.0082 & 0.3203 & 0.3915 & 3.5810 & 6.4833 \\
\hline & $(0.0104)$ & $(0.0002)$ & $(0.0917)$ & & & \\
\hline \multirow[t]{2}{*}{$\mathrm{UK}$} & -0.0796 & 0.0042 & 0.9752 & 0.3940 & 4.2062 & 9.9182 \\
\hline & $(0.0436)$ & $(0.0011)$ & $(0.1830)$ & & & \\
\hline \multirow[t]{2}{*}{ FR } & -0.1488 & 0.0047 & 0.6009 & 0.4314 & 8.4793 & 12.7324 \\
\hline & $(0.0233)$ & $(0.0007)$ & $(0.0829)$ & & & \\
\hline \multirow[t]{2}{*}{ GY } & -0.0847 & 0.0049 & 0.4259 & 0.2242 & 2.5970 & 5.1924 \\
\hline & $(0.0367)$ & $(0.0010)$ & $(0.0921)$ & & & \\
\hline \multicolumn{7}{|c|}{ FMLS - No prewithening } \\
\hline & Cnst & $(1-\sigma) \mu$ & $\sigma$ & $\mathrm{Lc}$ & MeanF & SupF \\
\hline \multirow[t]{2}{*}{$\mathrm{US}$} & -0.2165 & 0.0083 & 0.2865 & 0.3444 & 2.9204 & 5.6111 \\
\hline & $(0.0105)$ & $(0.0002)$ & $(0.0929)$ & & & \\
\hline \multirow[t]{2}{*}{ UK } & -0.1097 & 0.0049 & 0.8476 & 0.5917 & 4.4923 & 8.2295 \\
\hline & $(0.0337)$ & $(0.0008)$ & $(0.1414)$ & & & \\
\hline \multirow[t]{2}{*}{ FR } & -0.1568 & 0.0047 & 0.6264 & 0.2522 & 2.9542 & 6.6024 \\
\hline & $(0.0263)$ & $(0.0008)$ & $(0.0933)$ & & & \\
\hline \multirow[t]{2}{*}{ GY } & -0.0893 & 0.0050 & 0.4275 & 0.3954 & 4.1440 & 7.0142 \\
\hline & $(0.0290)$ & $(0.0008)$ & $(0.0727)$ & & & \\
\hline \multicolumn{7}{|c|}{ CCR - Prewithening } \\
\hline & Cnst & $(1-\sigma) \mu$ & $\sigma$ & $\mathrm{H}(0,1)$ & $\mathrm{H}(0,2)$ & $\mathrm{H}(1,2)$ \\
\hline \multirow[t]{2}{*}{ US } & -0.2150 & 0.0082 & 0.3178 & 2483.9183 & 2515.3571 & 0.2192 \\
\hline & $(0.0104$ & $(0.0002)$ & $(0.0894)$ & & & \\
\hline \multirow[t]{2}{*}{ UK } & -0.0962 & 0.0046 & 0.8973 & 26.2352 & 65.5756 & 5.6935 \\
\hline & $(0.0377$ & $(0.0009)$ & $(0.1514)$ & & & \\
\hline \multirow[t]{2}{*}{ FR } & -0.1481 & 0.0047 & 0.6043 & 44.4013 & 76.0244 & 7.0169 \\
\hline & $(0.0238)$ & $(0.0007)$ & $(0.0824)$ & & & \\
\hline \multirow[t]{2}{*}{ GY } & -0.0850 & 0.0049 & 0.4248 & 28.2294 & 102.7034 & 13.1393 \\
\hline & $(0.0353$ & $(0.0009)$ & $(0.0867)$ & & & \\
\hline \multicolumn{7}{|c|}{ CCR - No prewithening } \\
\hline & Cnst & $(1-\sigma) \mu$ & $\sigma$ & $\mathrm{H}(0,1)$ & $\mathrm{H}(0,2)$ & $\mathrm{H}(1,2)$ \\
\hline \multirow[t]{2}{*}{ US } & -0.2165 & 0.0083 & 0.2864 & 2512.8058 & 2637.2042 & 0.4190 \\
\hline & $(0.0104)$ & $(0.0002)$ & $(0.0882)$ & & & \\
\hline \multirow[t]{2}{*}{ UK } & -0.1121 & 0.0050 & 0.8359 & 39.7712 & 99.5992 & 8.3497 \\
\hline & $(0.0324)$ & $(0.0008)$ & $(0.1342)$ & & & \\
\hline \multirow[t]{2}{*}{ FR } & -0.1572 & 0.0047 & 0.6243 & 35.8554 & 63.6070 & 6.6481 \\
\hline & $(0.0269)$ & $(0.0008)$ & (0.0918) & & & \\
\hline \multirow[t]{2}{*}{ GY } & -0.0900 & 0.0050 & 0.4254 & 48.2654 & 232.2891 & 27.5639 \\
\hline & $(0.0275)$ & $(0.0007)$ & $(0.0670)$ & & & \\
\hline
\end{tabular}




\section{Appendix D: GMM estimates assuming a constant dis- count factor}

Table 8: GMM estimates (case A)

\begin{tabular}{|ccccccc|}
\hline & $\phi$ & $\nu$ & $1 / \gamma$ & $J_{\text {test }}$ & $t_{\phi=1}$ & SupLR \\
\hline US & 0.8656 & 0.0043 & 0.0340 & 17.2899 & -3.9946 & 8.2732 \\
& $(0.0336)$ & $(0.0004)$ & $(0.0068)$ & {$[0.3018]$} & {$[0.0025]$} & \\
UK & 0.8619 & 0.0010 & 0.0155 & 11.2143 & -3.6652 & 6.6536 \\
& $(0.0377)$ & $(0.0008)$ & $(0.0056)$ & {$[0.7373]$} & {$[0.0061]$} & \\
FR & 0.7542 & 0.0011 & 0.0096 & 10.9277 & -3.7991 & 14.5281 \\
& $(0.0647)$ & $(0.0004)$ & $(0.0017)$ & {$[0.7577]$} & {$[0.0042]$} & \\
GY & 0.8779 & 0.0013 & 0.0157 & 20.9957 & -3.3893 & 11.7453 \\
& $(0.0360)$ & $(0.0003)$ & $(0.0043)$ & {$[0.1370]$} & {$[0.0130]$} & \\
\hline
\end{tabular}

Table 9: GMM estimates (case B)

\begin{tabular}{|ccccccc|}
\hline & $\sigma$ & $(1-\sigma) \mu$ & $\nu$ & $1 / \gamma$ & $J_{\text {test }}$ & SupLR \\
\hline US & 0.9013 & 0.0057 & 0.0048 & 0.0327 & 21.7664 & 34.4595 \\
& $(0.0980)$ & $(0.0009)$ & $(0.0003)$ & $(0.0087)$ & {$[0.2425]$} & \\
UK & 0.9961 & 0.0031 & 0.0010 & 0.0150 & 14.4002 & 22.2567 \\
& $(0.1074)$ & $(0.0014)$ & $(0.0008)$ & $(0.0060)$ & {$[0.7027]$} & \\
FR & 0.6932 & 0.0040 & 0.0007 & 0.0109 & 15.0011 & 24.1962 \\
& $(0.0929)$ & $(0.0016)$ & $(0.0005)$ & $(0.0021)$ & {$[0.6619]$} & \\
GY & 0.1982 & 0.0073 & 0.0011 & 0.02449 & 27.9434 & 66.1297 \\
& $(0.0630)$ & $(0.0014)$ & $(0.0002)$ & $(0.0053)$ & {$[0.0629]$} & \\
\hline
\end{tabular}

